\title{
MILITARY HEALTH DEPENDENT ON CIVIL HEALTH
}

\author{
By J. C. Perry, M.D., \\ Assistant Surgeon-General, U. S. Public Health Service.
}

This article is limited to a discussion of the close relation between the health of the civil community and that in the military camps adjacent, as well as that in industrial centers in its relation to military productiveness. As the health and the resultant efficiency of our military forces are closely related to the health of our population as a whole, it becomes pertinent to show this intimate correlation between the two, both in its immediate and remote effects, and a brief consideration of remedial measures, both of a preventive and curative nature, is warranted.

Questions that naturally arise are what will be the effect on the national health as a result of the large number of doctors that will be required for military service, and will this drain leave insufficient aid for the care of the sick in the different communities. In answer it can be stated that due care is being exercised by the authorities in calling the medical reserve officers to active duty, in order that a sufficient number will be left in each community to care for the sick and maintain the national health at a satisfactory standard. Many doctors suffering from minor physical disabilities, sufficient to debar them from the strenuous life of a military officer, and others, will be left to provide this care and their work will be as patriotic as that performed by their more fortunate confrères. There would seem to be no need for alarm on this score because if 22,000 are called to active military service the number will be only about 15 per cent of the total number of physicians in the country.

However, the war and the consequent activities have brought about radical changes, especially in the industrial centers, that require a more active prosecution of preventive measures for maintenance of health, and the burden thrown on the health department and physicians of certain communities will tax the available medical force to the utmost. In this connection, it may be pointed out that many of our trained sanitarians have joined the colors, and as the science of public health is young and it has been only in recent years that proper study and attention have been given this subject, many 
of the trained workers in this activity are of an age that subject them to call for military duty and, consequently, it is probable that there may be an insufficient personnel in this particular phase of the health problem until the gap can be filled with female physicians trained in public health work.

National health as a factor in national efficiency can be properly considered both in its immediate and remote relation. Under immediate there are embraced:

I. The health in civil communities in relation to the troops in adjacent camps and cantonments.

2. The health in crowded industrial centers as a factor in national efficiency.

3. The safeguarding of the health of workers in the war industrial plants.

\section{Community Health vs. Health in Camps}

The protection of the soldiers from diseases in the civil communities deserves first consideration as its importance is paramount. The efficiency of a body of troops is largely dependent on the health of its individual members and a large sick list from preventable diseases is a reflection on the sanitary condition of the camp's environment, either within the camp or in the extra-cantonment area. The soldier deserves relaxation and entertainment but the place in which he seeks amusement must be in such a satisfactory sanitary condition that his pleasure will be free from a menace to his health.

Owing to the exigencies of war requiring a large number of trained soldiers with the least possible delay, camps and cantonments were rapidly erected throughout the country and filled with men before it was possible, in many instances, to sanitate thoroughly the adjacent towns and villages which would be visited by the men when on leave. This created at once a health problem of national importance and one of intimate bearing on national efficiency. In most of these places the local health organization was unable to cope with the situation because of insufficient funds and lack of personnel, and as the necessities arose on account of national activities it was proper that federal aid should be extended through the U. S. Public Health Service.

Realizing that an improvement in sanitary conditions was essential for the national health and that the occurrence of disease 
in these areas might result in impairing national efficiency in a most vital spot, that service has practically taken over sanitation around thirty-six camps and cantonments and two large government industrial plants. This action has been to assist, supplement, and develop the local health agencies, assuming direction of activities when requested, in order to establish a live and adequate health organization in the different extra-cantonment areas, so that all necessary sanitary work could be executed and maintained, not only for the protection of the civil population but especially to safeguard that of the soldiers by making the places they visit for amusement safe, in so far as concerns their health.

\section{Measures Taken to Insure the Public Health}

As the health of the nation is dependent on the health prevailing in the different units that comprise the total, and as the activities executed in specific areas affect the whole in this respect and have an important bearing on national efficiency, a brief enumeration of the measures being carried out to conserve the public health in these strategic centers may be permissible, because the results accomplished have an important bearing not only on the national health but also on national efficiency in protecting the health of our fighting forces.

Particular attention is directed to the report and control of communicable diseases; the prevention and control of venereal diseases; and the active prosecution of anti-malarial measures.

It seems proper to point out that the successful prosecution of the activities mentioned constitute the important measures for maintaining health in the civil communities to a standard that will minimize the danger of lessened efficiency in our military and industrial armies. This is especially true as regards social diseases, and now that the veil of secrecy has been lifted a mention of this subject is permissible. No other diseases so impair the efficiency of a fighting force as this infection. The control of social diseases is of paramount importance to the military establishment as they are the greatest cause of disability in the army. A solution of this problem is difficult, and sanitarians and social workers approach it from different angles, but the curse of this infection is so far-reaching in its effects, that the ablest thinkers in many walks of life have become aroused to the necessity for a more active prosecution of measures 
for the control of these diseases. For immediate results it would seem that the enforcement of prophylactic and curative measures would yield the most benefit, and this is what is being done in the extra-cantonment zones, but the education of the young in sex matters and an appeal to their moral forces will probably be the final solution of this problem.

Of the directly communicable diseases, mention will be made only of cerebro-spinal meningitis as it is often a dread of camp life, and the results in its control have been so good that this fact is worthy of mention. Outbreaks have occurred in areas adjacent to cantonments but energetic measures have been executed immediately so that the disease has been promptly suppressed and little danger has resulted to the health of the military forces.

The danger of malarial infection at a number of camps and cantonments in the South constituted at one time a health problem of some magnitude, but intense anti-malarial measures have been instituted and are being so successfully prosecuted that it is believed that this danger will be obviated. Of course, it can be readily understood that the measures being carried out in these areas protect the health of the civil population as well as that of the military forces, and with this resultant diminution of disease in the extracantonment areas, the health and efficiency of the soldiers are still further safeguarded.

\section{Treatment of Disease in Industrial Centers}

Another important phase of the national health problem and one that is intimately related to our national efficiency at this time is the prevention of the occurrence and spread of disease in the crowded industrial centers, for a condition has been brought about by war activities that must receive remedial attention if our maximum efficiency is to be kept up. It is as vital to maintain the health of our army of workers as it is that of our military forces, because the successful prosecution of the war is directly dependent upon the output of labor and every means must be exercised to maintain the health of these workers to the highest standard of efficiency.

There has been created such a demand for laborers in the various factories engaged in producing articles essential for our military activities that the population in these industrial centers has more than doubled, and the housing accommodations have not kept pace with the increase in the number that must have living quarters. 
The result has been a marked overcrowding and a creation of unsanitary conditions that is conducive to sickness and a lowering of the general efficiency of these workers. This is apart from health hazards due to occupation, which will receive consideration later.

The housing problem has become acute in many places and it is difficult to formulate feasible plans for its solution on account of the difficulty of securing, shipping, and erecting into dwellings the necessary materials at a time when the railroads are required for the purpose of transporting freight intimately connected with war activities and when laborers are demanded for work in the war industrial plants. Houses that provide homes for the normal population must now shelter three times as many, and this large increase in the population has thrown an extra strain on what at times is an already inadequate health department. In many places the community's public health service has not enlarged to meet the rapidly expanding needs. This density of population, together with the shifting of workers from place to place in search of high wages creates a condition that is ripe for the dissemination of disease.

At any time the least undue prevalence of disease is a serious matter, but now when our successful prosecution of the war depends upon the efficiency of this army of workers behind the lines it becomes imperative that every individual laborer should be guarded against the occurrence of any illness that would impair his capacity for labor and prevent a maximum result from his efforts. This phase of the national health problem is not fanciful but real, and is one that is fraught with danger. In many of these industrial centers there is such congestion that the laborers who have families are forced to live under crowded and insanitary conditions and it is here that the danger exists. The sanitary condition in the factory may be excellent but the worker is thus safeguarded only one-third of his time and the conditions under which he is forced to live do not prevent him from acquiring infection in his home environment.

This problem has already engaged the attention of our captains of industry as well as public health officials generally, and the crying need for enlargement, concentration, and coördination of effort has been foreseen in a request for a sanitary reserve corps of the U. S. Public Health Service. This need for an enlarged sanitary corps to meet the conditions brought about by our war activities is apparent to all who have given this phase of the health problem serious consideration. 


\section{Health OF WORKERS IN WaR INDUSTRIES}

A third division of this problem is the protection of the health of those employed in the war industrial plants. Since the commencement of the war and especially since the entrance of the United States into the conflict numerous new and enlarged industrial plants have sprung into existence as an essential part of the "Win-theWar" program, and the maintenance of a maximum output of war materials is so vital to our success that the preservation of the health of the employes in these factories must receive the most earnest consideration. At no time has the efficiency of labor been of such paramount importance, for the national necessity demands that these war industries maintain the highest degree of production and that industrial labor be kept at a maximum degree of efficiency as an essential for the prosecution of the war to a successful termination. Therefore, our results will depend on the energy and good health of these workers, and every effort should be made and every means should be applied to safeguard them against disease or injury. Continuous good health is necessary for a continuous maximum production.

The conditions surrounding war industries often involve health hazards and these are not confined only to the manufacture of munitions and explosives but occur also in the allied industries that produce other war material. Furthermore, in an effort to maintain the maximum output or to increase one's earnings on account of the high wages paid there often results overfatigue, which defeats the object sought to be accomplished by overexertion or overtime.

It is not necessary to enter into an extended discussion of industrial hygiene, even if space would permit, to show the necessity for the medical care of these employes and the supervision of the sanitary conditions under which they work as an important determining factor in national efficiency. This subject is a health problem of national importance and calls for more intensive study in order to determine more clearly the causative factors of these diseases so that proper remedial or preventive measures may be employed. Investigations and studies of this character, as well as the supervision of the health of industrial workers, would seem to be a function of the federal government. Studies on overfatigue and health hazards of those employed in factories manufacturing munitions and explosives have been carried out, and it is believed that a useful 
extension of federal activities would be an active coöperation with state and local health authorities as a coördinating and unifying agency in the adoption of standard measures for the protection of industrial workers, as the health of this class of laborers is a national asset and our efficiency is directly related to the standard at which it is maintained.

This discussion could be extended to include workers in other lines of activities, in all of which their health is a measure of their efficiency, but this does not seem necessary. However, our railroads and ships and their efficient operation are so vital to a successful prosecution of the war that the health of workers engaged therein becomes at once a matter of greatest importance.

\section{Health of School Children}

While this has been little more than a brief outline of the health problem in its immediate relation to national efficiency, it is believed that sufficient has been said to point out the salient features in this respect, and mention will now be made of a more remote factor in relation to national health in determining efficiency. This is school hygiene. The active prosecution of school hygiene is an activity of great value and, as in times of stress the safety of a country depends essentially on its man power, it becomes obvious that any measure that will conserve that power deserves careful attention. The large number of rejections in the selective draft shows forcibly the need for more extended supervision of the health of school children, as a great number of the defects causing rejection had their origin during the period of growth and development.

The existence of large numbers of preventable defects among school children has been shown by intensive investigations of school hygiene. The prevention of these defects is especially important in rural communities, because these children, under existing conditions, cannot receive the attention of specialists that are available for the children in city schools. Furthermore, they are not as efficiently protected as a group by health laws as in cities and are therefore adversely affected to a greater degree by diseases that lower vital resistance and interfere with proper physical and mental development. When those suffering from defects grow up to manhood they often do not reach the proper health standard to be able to render a maximum efficiency to their country. 